\title{
La dimensión política del Mercosur: actores, politización y ideologia
}

\author{
MONICA HIRST
}

A CTUALMENTE SE HA AVANZADO más en el análisis y el debate sobre el significado económico que sobre el sentido político del Mercosur. No obstante, a medida que se profundizan y diversifican los temas de su agenda se torna importante comprender las consecuencias políticas del proceso de integración subregional.

Un análisis político del Mercosur debe partir de su caracterización como un proceso intergubernamental cuyo avance ha sido influenciado por dos tipos de factores; los de carácter exógeno y endógeno. Los primeros comprenden las políticas económicas, las políticas exteriores y las dinámicas políticas internas de cada Estado miembro; los segundos se refieren a los aspectos institucional-burocráticos, socioeconómicos y político-ideológicos vinculados a los procesos de integración regional. Sin embargo, dado que el eje Argentina-Brasil constituye el núcleo político del proceso asociativo, el peso de los factores señalados, particularmente los de carácter exógeno, no será igual para todos los Estados miembros.

Asimismo, un análisis político del Mercosur debe tomar en cuenta los condicionantes externos resultantes de la economía política internacional. Para los países que participan de esta iniciativa la vinculación con el proceso de globalización, que se caracteriza por un crecimiento más rápido de las variables internacionales vis- $a$ - -is las variables nacionales, se tornó el principal incentivo para la adopción de una estrategia de regionalismo abierto (1). Utilizada como un instrumento para estimular nuevas oportunidades de comercio e inversiones, esta asociación fue percibida como un medio para perfeccionar la competitividad internacional de sus socios. Cabe destacar que pese a que un proceso integracionista de esta naturaleza genera realidades crecientemente homogéneas, la permanencia de heterogeneidades nacionales otorga una especificidad política al Mercosur. Esta especificidad está dada en función de tres aspectos políticos claves del proceso de integración subregional: la actuación de sus diferentes actores (burocráticos, políticos y sociales), sus temas de politización y su base de sustentación ideológica. 


\section{Los actores}

Actualmente se puede identificar dos tipos de actores en el Mercosur; los de primer y segundo nivel. Se trata de una diferenciación en el grado de participación, determinada por condicionantes económicos y políticos y por el formato institucional del propio proceso asociativo. En el primer nivel se ubican la burocracia, los grupos empresarios y las máximas dirigencias políticas; en tanto que en el segundo nivel se sitúan los partidos políticos, organizaciones sindicales y los movimientos sociales.

\section{Actores del primer nivel}

\section{Los mercócratas}

Más allá de una pequeña burocracia para fines administrativos que opera desde una Secretaría en Montevideo, en todos los países miembros del Mercosur existe un cuerpo de funcionarios gubernamentales en los ministerios de relaciones exteriores y en las agencias económicas especializadas que conducen el proceso de integración subregional. Los diplomáticos más antiguos involucrados en el proceso poseen la experiencia de ALALC-ALADI como la principal escuela de formación para el desempeño de esta tarea. Pero las frustraciones resultantes de estas experiencias sumadas al impacto de las nuevas realidades domésticas e internacionales estimularon un aggiornamento de mentalidades que permitieron intergubernamental. Para la mayoría de los funcionarios vinculados a temas integracionistas, el Mercosur es un proceso de learning-by-doing donde las posiciones e intereses de las políticas externas de sus respectivos gobiernos deben armonizarse con los de un proceso de negociación minilateral.

Durante la primera mitad de los años noventa las negociaciones intergubernamentales en torno del Mercosur se tornaron el campo más activo de la diplomacia económica de sus países miembros. Esta experiencia no condujo a la formación de una elite tecnocrática al estilo del modelo comunitario europeo donde se dio una creciente disociación entre las dinámicas políticas locales y la construcción de un proyecto integracionista (2). En el caso del Mercosur, sin embargo, los equipos técnicos operan desde las cancillerías y además dependen de la aprobación de sus respectivos gobiernos, a los que deben rendirles cuentas sobre el resultado de cada negociación. Asimismo, cuando se cumple una agenda común de negociaciones, como ocurre en el ámbito de los diferentes subgrupos de trabajo, los avances logrados resultan simultáneamente de entendimientos inter e intragubernamentales.

El actual dinamismo del proceso subregional viene generando nuevos desafíos para los diplomáticos, particularmente en lo que respecta a los intereses y presiones que surgen en el frente interno. Este tipo de desafío está relacionado 
al carácter interméstico de un proceso de integración expansivo a medida que se amplia y se profundiza su agenda. En este caso, las cancillerias deben enfrentar presiones e intereses internos proveniente de tres ámbitos:

- otras agencias del Estado - principalmente económicos - que tienen una injerencia cada vez mayor en las negociaciones intergubernamentales, tornándose crecientemente importante la coordinación interburocrática con otros ministerios (3);

- los intereses societales afectados positiva y/o negativamente por las negociaciones intergubernamentales. Los contactos y consultas con sectores empresarios locales se tornaron decisivos en el logro de entendimientos entre los países de la región;

- los gobiernos estaduales/provinciales de regiones beneficiadas o perjudicadas por el avance del proceso integracionista. Se destacan dos tipos de provincias, las que se encuentran en regiones fronterizas y aquellas cuyas producciones serán especialmente afectadas por la asociación intrarregional. Es interesante mencionar la activación de comités y consulados en las fronteras - reuniendo funcionarios diplomáticos con autoridades locales - que deben cubrir una agenda cadavez más compleja dedicándose a temas como: a cuestiones migratorias, la ocupación indebida de tierras, protección del medio ambiente y actividades de contrabando (4).

A las nuevos desafios domésticos, los mercócratas deben agregar una extensa agenda de negociaciones internacionales. Cabe destacar que existen notables diferencias entre lidiar con un proceso de integración de estrategia endógena al estilo de los años '60 y '70, y la conducción de lo que se llama actualmente un modelo de integración abierta. Las negociaciones con el NAFTA, y en particular con los Estados Unidos, con la Unión Europea y con otros bloques regionales o paises individuales constituyen los principales temas de la agenda externa del Mercosur. La importancia de estas negociaciones es diversa, debiendo atender calendarios y cronogramas prefijados que raramente pueden ser cumplidos. Cabe subrayar aquí el apoyo técnico y académico con el cual los mercócratas pasaron a contar en los últimos tiempos tanto para profundizar el debate como clarificar las opciones que tienen por delante (5).

En este contexto se creó una vinculación de cuestiones que muchas veces erosiona la frontera entre lo internacional y lo nacional y entre la política y la economía. Cuestiones como disputas fronterizas, uso compartido de fuentes energéticas, comunicaciones, seguridad y política internacional pasaron a estar relacionados con la creación de un espacio económico ampliado. 


\section{El empresariado}

Otro actor relevante en el Mercosur ha sido el segmento empresario, que representa los intereses de los grupos económicos de mayor peso o las empresas transnacionales que operan en la subregión. Habiendo aceptado la creación de un espacio económico integrado como un mal inevitable, los sectores industriales y financieros nacionales más dinámicos, especialmente en la Argentina y en el Brasil, pasaron a percibir la asociación intrarregional como una forma de aprendizaje para la adopción de estrategias empresarias más competitivas. $\mathrm{Al}$ abandonar su "posicionalismo defensivo" este segmento se mostró interesado por la ampliación de redes transfronterizas que les permitiria combinar el impacto de políticas de estabilización con acuerdos preferenciales de comercio (6).

Se debe diferenciar en el Mercosur la actuación de las empresas transnacionales, los grandes grupos nacionales, y los medianos y pequeños productores (7). El primer sector goza de un alto grado de autonomía habiendo adoptado estrategias de regionalización que son beneficiadas más podrían casi siempre implementarse de forma independiente al proceso de integración regional (8). El segundo grupo es el que ha mostrado mayor agilidad política habiendo buscado una estrategia que equilibre los beneficios provenientes de los procesos de reforma doméstica con el impacto de la creación de un mercado ampliado. Las estrategias y alianzas empresarias en el caso de ambos sectores poseen cierto grado de autonomía vis-a-pis el proceso de negociación intergubernamental. De hecho, la regionalización se tornó un estímulo aún cuando no existen acuerdos integracionistas que respalden políticamente operaciones transnacionales como ocurre en el caso de la creciente presencia de empresas chilenas en Argentina (9). Cabría también indagar si las 400 empresas brasileñas que actualmente operan en la Argentina estarían allí si no se hubiese firmado el Tratado de Asunción.

El interés de las medianas y pequeñas empresas por los procesos de integración subregional está en gran medida determinado por su capacidad de vinculación con los dos sectores anteriormente mencionados. La principal fuente de oportunidades para estas empresas reside en el proceso de tercerización impulsado por las industrias de gran tamaño - nacionales e internacionales - que abre el espacio para los llamados nichos de especialización intraindustrial.

A partir de los años noventa se produjo un importante incremento en las transacciones interempresarias mediante acuerdos de distribución, la formación de tradings o el montaje de firmas de representación. Al mismo tiempo creció el flujo de inversiones transfronterizas estimulado por las privatizaciones llevadas adelante en toda la subregión (10). Este constituye un proceso con notables desigualdades en nivel nacional y subregional, debido a las asimetrías subregionales o a las diferencias de recursos económicos y políticos de que disponen las empresas. Estas desigualdades a su vez no son generadas necesaria y exclusivamente 
por la formación de un mercado ampliado, siendo muchas veces el resultado de los programas de reforma económica implementados previa o simultáneamente por los gobiernos locales.

Comparativamente con otras regiones, a pesar de una participación más activa que en otros períodos, el empresariado de los países del Mercosur tienen por delante un largo camino para perfeccionar las formas de representación de sus intereses en el proceso de integración subregional (11). Cabe, entre tanto, preguntarse si el interés por una mayor institucionalización de esta representación constituye una verdadera aspiración de este sector, principalmente por parte de sus grupos más poderosos. Entre las decisiones adoptadas en la reunión de Ouro Preto a fines de 1994 se destaca la creación de un Foro Consultivo Económico Social cuya principal función sería dar mayor organicidad y sentido regional a los intereses empresarios. No obstante, un año después los avances en esta dirección fueron mínimos, observándose una clara preferencia por priorizar los canales informales de presión o las prácticas de lobby ya desarrolladas en nivel nacional (12).

\section{Las máximas dirigencias políticas}

La voluntad presidencial se ha transformado en un elemento central en las negociaciones del Mercosur lo cual permite afirmar que este es actualmente mas un proyecto de gobiernos que de Estados. El interés de los primeros mandatarios por la integración regional no deriva de programas partidarios o de ideales políticos específicos. El interés de los gobernantes mercosuleños por la continuidad y la profundización del proceso no está ligado tampoco a estrategias populistas como ocurría en el pasado (13). Se trata de un interés político muy particular que procura conjugar liderazgo personal, sentido de oportunidad economica y necesidad de proyección internacional.

Para el Mercosur, como también para el PICE durante la etapa anterior, la voluntad presidencial se tornó un elemento importante tanto para fortalecer el proceso como para establecer sus límites. El hecho de que esta voluntad no esté identificada con programas partidarios ha favorecido su continuidad de un gobierno a otro. En realidad, el tema de la integración regional ha sido el punto de menor divergencia entre los gobiernos de la subregión, lo que redujo la necesidad de instituciones comunitarias desde un principio. Desde la firma del Tratado de Asunción, el cambio de presidentes y de partidos gobernantes no tuvieron mayor impacto sobre el proceso de integración subregional. En la mayoría de los países del área, este fue un tema de politización interna marginal. No cabe duda de que el pasaje del PICE al Mercosur en los años 1989-91, que coincide con los cambios de gobierno en la Argentina, Brasil y Uruguay corresponde a un viraje importante en cuanto a la estrategia integracionista adoptada. No obstante, este viraje estuvo vinculado a nuevas premisas de política económica, comprometidas 
en mayor o menor grado con un ideario neoliberal. Contrariamente a las expectativas iniciales, la voluntad integracionista se mantuvo y se vio fortalecida entre los países del Mercosur. Aún en el Uruguay, donde esta fue un tema de politización durante la campaña presidencial de 1994, predominaron las señales favorables a la continuidad de la participación uruguaya en el proceso asociativo.

\section{Actores del segundo nivel}

El segundo nivel de actores está constituido por los partidos políticos, organizaciones sindicales y pequeños y medianos empresarios. En gran medida la posición secundaria de estos actores está relacionada a los procesos de democratización experimentados por los países de la subregión (14). A pesar de que en todos los casos se observa la vigencia de regímenes políticos democráticos, la capacidad de organización de los intereses de estos actores es insuficiente para asegurar su presencia activa como fuerza formateadora del Mercosur. En este sentido, la vinculación entre la profundización de la democracia y de la regionalización carece aún de canales institucionales y organización política adecuada.

Se advierte un contraste notable entre las experiencias de las sociedades industriales europeas y lo que se observa en los países del Mercosur. La influencia ejercida por estos actores en el actual proceso comunitario europeo e incluso en los Estados Unidos y Canadá, donde el grado de institucionalización del NAFTA es limitado, es lejos mas significativa. En la Unión Europea, las articulaciones interpartidarias cumplieron un rol decisivo para la ampliación de las funciones del Parlamento Europeo después del Acta Única Europea, y la red de vinculaciones intersindicales vienen cumpliendo un papel crucial en la conducción de la agenda social pos-Maastricht. En el caso del NAFTA, los sindicatos y las organizaciones no gubernamentales norteamericanas se transformaron en actores protagónicos en la definición de pautas de negociación intergubernamentales - especialmente durante la segunda etapa cuando se negoció un acuerdo paralelo sobre temas laborales (15).

A continuación se examinará brevemente el tipo de actuación observado en el caso del Mercosur, de la clase parlamentaria, de las organizaciones sindicales y de los pequeños y medianos empresarios.

\section{Los partidos políticos}

La participación del medio político-partidario ha sido marginal en el Mercosur. El Tratado de Asunción previó en su artículo 24 la creación de una Comisión Interparlamentaria, sin atribuirle una función específica. Una vez constituida, la propia comisión determinó que sus atribuciones serian de carácter consultivo, deliberativo y de formulación de propuestas. De hecho, sus vínculos 
con los órganos técnicos del Mercosur han sido informales e inconstantes, llevando a que la movilización parlamentaria en torno a la agenda integracionista sea limitada y/o desarticulada.

Contrariamente a lo que se observa en la experiencia europea, los partidos políticos de los países del Mercosur no cuentan con redes interpartidarias que promuevan prácticas interactivas en la subregión. Tampoco existe un parentesco ideológico y/o programático que estimule este tipo de interacción. Cada país tiene una estructura partidista propia y sus programas no encuentran correspondencia político-ideológica en los otros países, lo que explica la dificultad para crear una trama de intereses y posiciones comunes que no se limite a la defensa de la democracia.

En el ambito politico interno, la participación de Argentina en el Mercosur corresponde a un proyecto bipartidista, y este ha sido, de hecho, el único punto de continuidad entre las políticas exteriores de los gobiernos radical y justicialista. Entre tanto, la preocupación del Congreso por el tema integracionista ha sido fragmentada y dispersa, inclusive en momentos de tensión y politización de las negociaciones subregionales. En Brasil, el interés por el Mercosur se concentra en los representantes de los Estados del sur del país, preocupados casi siempre por los costos de este proceso para los agricultores del área. También se observa una preocupación por parte de sectores nacionalistas brasileños, particularmente de los partidos de izquierda, que perciben la vinculación con Argentina como una forma de profundizar la influencia de recetas neoliberales sobre las políticas locales. En el caso uruguayo, la movilización parlamentaria frente al Mercosur fue mayor en la etapa inicial, cuando el gobierno buscó asegurar un amplio apoyo interno a su decisión de adherir al Tratado de Asunción. En cambio, en Paraguay, la clase política, y en especial los sectores más duros del partido gobernante, representa uno de los focos de cuestionamiento a la participación del país en el Mercosur.

\section{Los pequeños y medianos empresarios}

Frente a las políticas unilaterales de liberalización comercial, los pequeños y medianos empresarios han sido forzados a abandonar las prácticas defensivas utilizadas durante el período de vigencia del modelo sustitutivo. A esto se sumó el Programa de Liberación Comercial del Acta de Buenos Aires y el Tratado de Asunción que impusieron nuevas reglas del comercio intrarregional. Esto condujo, en algunos casos, a que las medianas y pequeñas empresas desarrollaran nuevas estrategias con el fin de mejorar la competitividad y el acceso a los mercados de la región. No obstante, tratándose de una cantidad aproximada de 3,5 millones de unidades cuando se incluyen las microempresas, este sector productivo pasó a reclamar programas de apoyo que le permita enfrentar las nuevas condiciones competitivas impuestas por el Mercosur (16). 
Para estas empresas se tornó crecientemente importante encarar las necesidades de reconversión, de cambios de gestión, de actualización tecnológica, de búsqueda de socios y de formas de acceder a nuevos mercados - dentro y fuera del Mercosur (17). En este contexto se tornó vital la obtención de apoyos públicos para reduzir costos de producción y mejorar las condiciones de financiación e inversión. Para las firmas de pequeño y mediano tamaño, las limitaciones impuestas por las políticas nacionales para lograr este tipo de apoyo, la inestabilidad macroeconómica y los ajustes impuestos por las nuevas estrategias productivas de las empresas transnacionales incrementó aun más su vulnerabilidad.

En el ámbito del Mercosur, los mecanismos institucionales y las fuentes de apoyo público en Brasil, aunque insatisfactorias desde el punto de vista local, han sido superiores a las que ofrecen sus socios para lidiar con este tipo de adversidad. En general, las PYMES argentinas y uruguayas encuentran dificultades para mantener un nivel competitivo frente a sus pares brasileñas. Las reacciones generadas por el abandono de una estrategia industrialista en el contexto de una asociación económica con Brasil se ven agravadas por la ausencia de convergencias entre las políticas públicas de estos países. La respuesta del gobierno argentino ha consistido en medidas proteccionistas ocasionales, algunas que contradicen los compromisos establecidos por el Tratado de Asunción. En este cuadro, la creación de un instrumento propio en el ámbito del proceso asociativo para la canalización de demandas que atenúen los costos de integración se tornó una meta política de las micro, pequeñas y medianas empresas en la subregión.

\section{Las organizaciones laborales}

Los riesgos de que el proceso de integración reduzca los puestos de trabajo, genere nuevas prácticas de dumping social e incremente aún más el desempleo constituyen las principales preocupaciones de los líderes sindicales de la subregión (18). La preocupación dominante en este caso pasó a ser la articulación entre el Mercosur y el proceso de internacionalización de mercados en el cual la reducción de los costos de producción - incluyendo la mano de obra - se ha tornado una condición necesaria para mejorar la competitividad local. En este contexto la defensa del empleo corresponde a una prioridad de la agenda sindical del Mercosur, presentándose como principal desafío el desarrollo de una acción regionalizada en este sentido (19).

A pesar de que, en cada caso, la actuación de las organizaciones sindicales está sujeta a diferentes contextos políticos, comienza a emerger una agenda de intereses laborales comunes. El primer paso ha sido la homogeneización de las pautas internacionales de las políticas laborales de los cuatro países, en especial la adhesión a los convenios de la OIT. En segundo lugar, empezaron las negociaciones de la redacción de una Carta de los Derechos Fundamentales para el Mercosur 
con el objeto de crear un instrumento básico para la construcción de un sistema laboral integrado donde se definan normas y mecanismos de control para la protección laboral y social en la subregión. Entre los temas más debatidos para la elaboración de este documento se destacan: la penalización cuando se observen situaciones de dumping social y la libre circulación de la mano de obra. Con respecto al primer tema se destaca una propuesta argentina para prever medidas compensatorias para el país afectado en tanto que Brasil, manteniendo la misma posición que defende en la OMC, ha sido contrario al empleo de medidas de control supranacional para el tratamiento de temas laborales. Con respecto a la circulación de mano de obra tanto Argentina como Uruguay no pudieron contar con el apoyo paraguayo y brasileño para incluir algunas restricciones que impidiesen una liberalización plena.

En el ámbito del subgrupo $\mathrm{n}^{\circ} \mathrm{ll}$ dedicado a los temas laborales, las representaciones sindicales del Mercosur analizan, con los funcionarios de gobierno y los representantes empresariales, temas tales como: la permanencia y/o residencia del trabajador; el reconocimiento de títulos profesionales; las condiciones de seguridad en el trabajo y la armonización de las legislaciones laborales. La comisión de Empleo y de Formación Profesional se ha tornado una de las comisiones más activas dentro del subgrupo de trabajo $n^{\circ} 11$. En el ámbito de las organizaciones sindicales regionales, el proceso de Mercosur fue particularmente importante para ampliar el activismo y la representatividad de la Coordinación de las Centrales Sindicales del Cono Sur (CCSCS) creada desde 1986 (que también incluye a Chile).

Para los líderes sindicales argentinos, el Mercosur constituye más una fuente de preocupación que de movilización. Se teme que las dificultades para competir con productos brasileños legitimen políticas de flexibilización laboral así como también que la libre circulación de mano de obra abra las puertas para un aluvión migratorio e incremente aun más las tasas de desempleo en Argentina. El hecho de que el sindicalismo argentino atraviese un período de fragmentación y desmovilización reduce su capacidad de presión sobre el proceso integracionista y conduce a una actuación de bajo perfil por parte de instituciones poderosas como la Confederación General del Trabajo (CGT). En este marco, las posturas asumidas por las dirigencias sindicales en las reuniones del subgrupo $\mathrm{n}^{\circ} 11$ han sido más próximas a la de los sectores empresariales de su país de lo que ocurre en el caso de las representaciones uruguayas y brasileñas.

En Brasil, el Mercosur ha generado una creciente movilización del sector sindical, tanto en función de sus potenciales consecuencias sobre el mercado de trabajo como por la percepción de que este proceso podría transformarse en un instrumento de proyección subregional de los modelos políticos de organización laboral de este país. La actuación del sindicalismo brasileño en el Mercosur, y en 
particular de la Confederación Única de Trabajadores (CUT) esta motivada principalmente por el interés de evitar una expansión de las políticas de liberalización del mercado de trabajo siguiendo el ejemplo de lo que ocurrió en Chile. En el caso de Uruguay, el Plenario Intersindical de Trabajadores/Convención Nacional de Trabajadores (PIT-CNT) se vienen esforzando para fortalecer sus canales de comunicación con los empresarios y el Estado con vistas a asegurar un pacto nacional para la conducción de las negociaciones intra-Mercosur (20).

Las centrales sindicales de los países del Mercosur están preocupados con las políticas adoptadas por las empresas multinacionales que por operar con estrategias productivas regionales lleguen a ignorar especificidades nacionales y sectoriales en las negociaciones salariales. En este cuadro se torna aun más difícil la opción entre estrategias centralizadas o descentralizadas de las negociaciones patronales en el Mercosur. El primer tipo corresponde a una consecuencia de un sindicalismo transnacionalizado que opere con sistemas sindicales monopolistas, en tanto que se observa que en todo el mundo los modelos sindicales descentralizados son más exitosos en sus negociaciones patronales. Por su parte, la descentralización deberá profundizar una fragmentación de la acción sindical en el ámbito del Mercosur tornando mas difícil la construcción de una acción política que permita al sector sindical en su conjunto ascender del segundo al primer nivel en la estructura de decisión del Mercosur.

De hecho, la posibilidad de este ascenso está más condicionada por el poder de influencia y presión ejercido en los diferentes ámbitos nacionales que en un espacio regional. Por eso mismo las centrales sindicales actúan mayormente a través de sus respectivos gobiernos aún cuando estos no son percibidos como sus principales aliados. Esta paradoja refuerza, desde la óptica de los intereses económico-sociales en cada país miembro, actitudes defensivas frente al proceso de integración subregional. Este tipo de ambigüedad resulta de divisiones intra e intersindicales entre posiciones internacionalistas y proteccionistas (21). Este constituye el principal dilema ideológico para las organizaciones laborales en el Mercosur.

\section{Los puntos de politización}

La profundización de la agenda del Mercosur viene dilatando simultáneamente el espacio de controversia dentro y entre sus países miembros. Tanto soluciones técnicas como decisiones estratégicas tienden a politizarse en función de la multiplicidad de actores e intereses envueltos en el proceso asociativo. Al mismo tiempo el impacto homogeneizante del proceso de globalización aumenta las semejanzas entre los países de la subregión y las sociedades phuralistas modernas.

Observase en este cuadro una politización en el Mercosur que va más allá de una mera discusión técnico-burocrática donde el aumento de los puntos de 
convergencia no impide el surgimiento de nuevas diferencias. Como afirma Joseph Nye, en cualquier proceso de integración regional la "capa protectora de la 'nocontroversialidad' se gasta rápidamente a medida que los intereses más sensibles son tocados y que sube la temperatura política generada por el proceso de integración" (22). De acuerdo con este mismo autor existen procesos de integración en el que las cuestiones económicas son altamente politizadas desde el primer momento, lo que impide el uso de una capa protectora incluso en su etapa fundacional. En el caso del Mercosur esta descripción es parcialmente adecuada por tratarse de un proceso asociativo que ha presentado desde su etapa formativa picos de alta tensión para después retornar a la normalidad.

En sus primeros análisis sobre los procesos de integración regional, Nye llamaba la atención sobre el hecho de que la politización ocurre cuando “... un número mayor de grupos se envuelven en función de los efectos de la expansión de transacciones, vinculaciones anteriores, o la formación de coaliciones deliberadas. Cuanto mayor es este número, mayor es la posibilidad de interpretaciones divergentes sobre el interés común en un proceso de integración. La ampliación de los poderes de instituciones centrales no solamente se torna más visible para la opinión popular sino también estimula la acción de los grupos que se oponen a la integración, incluyendo los burócratas nacionales, preocupados por un avance sobre sus poderes" (23) Para que esta dinámica pueda mantener un carácter incremental se torna decisiva la creación de nichos políticos positivos, tanto en los diferentes ámbitos nacionales como en nivel supranacional, que apoyen el proceso de interdependencia estimulado por los nuevos vínculos económicocomerciales.

En el Cono Sur la politización generada por la integración regional involucra nuevas y antiguas cuestiones en las que se superponen intereses nacionales y estrategias comunes. Es necesario aclarar que un análisis de la politización en el Mercosur no puede excluir a Chile, que pese a que no es un miembro de esta asociación, influye y absorbe los debates generados en el ámbito del proceso integracionista. De hecho, su ausencia se ha tornado una forma de marcar su presencia.

En una breve clasificación de la politizacion en el Mercosur se pueden identificar cuatro universos temáticos que generan controversias entre y dentro de los países de la subregión. El primero esta ligado al universo de la economía política internacional, el segundo a la economía política doméstica, el tercero a la política exterior y de seguridad internacional y el cuarto a las opciones de institucionalización del proceso asociativo. En cada temática las controversias provienen del impacto diferenciado de la integración subregional sobre cada Estado miembro. 


\section{La economia politica internacional}

En el campo de la economía política internacional las controversias generadas se refieren al tipo de estrategia adecuado para enfrentar desafíos y oportunidades impuestos por nuevos desarrollos en el ámbito económico externo.

Obligados a aceptar reglas de acceso selectivo a los mercados de los países industrializados, las economías de la subregión tratan de asegurar mayor reciprocidad por sus políticas de liberalización unilateral. La compatibilización de legislaciones locales con las nuevas reglas de funcionamiento del sistema de comercio internacional y la vinculación positiva con los espacios económicos regionales corresponden a una preocupación compartida por todos los Estados miembros del Mercosur. No obstante, coexisten tipos diferenciados de estrategias económicas externas, condiciones desiguales de competencia empresarial, afinidades político-culturales diversas, y recursos institucionales de escala diferentes. $\mathrm{Al}$ mismo tiempo que la concepción del Mercosur como una experiencia de regionalismo abierto se tornó una manera de emitir una señal positiva para la comunidad económica internacional, se creó un nuevo tipo de tensión dentro del Mercosur. Por un lado, la convivencia entre los diferentes sistemas institucionales de economía de mercado abrió un espacio para una disputa velada por buenas inversiones (24). Por otro, la yuxtaposición de influencias e intereses externos, particularmente de los Estados Unidos y de la Unión Europea, generó la necesidad de lograr la armonización de una agenda de negociaciones internacionales donde se busca sumar las ventajas del status de comerciante global con las de pertenecer a un bloque comercial (25).

Es en este contexto que se traban los debates abiertos y silenciosos sobre la estrategia internacional del Mercosur. En su fase constitutiva la principal controversia giró en torno a la percepción de que la profundización del proceso subregional y sus vinculaciones con los Estados Unidos fuesen opciones excluyentes. Se desarrolló entonces un debate sobre los costos y beneficios de aceptar un patrón NAFTA de negociación con el gobierno norteamericano (26). Este debate fue superado con la reunión de la Cumbre de Miami a partir de la cual se creó una agenda de conversaciones más sistemáticas entre los Estados Unidos y el Mercosur.

También se puede prever un área de politización relacionado a las negociaciones UE-Mercosur. A partir de la firma del acuerdo interregional de diciembre último se abre una nueva etapa de conversaciones entre dos bloques que podrá suscitar diferencias en cuanto a los costos y benefícios de las concesiones a ser otorgadas para tener acceso al mercado comunitário. 
Otros temas controvertidos han sido el sentido prioritario o no de un Acuerdo de Libre Comercio Sudamericano para fortalecer la integración subregional y el tipo de vinculación a establecerse entre Chile y el Mercosur (27). Seguramente surgirán nuevos temas controversiales en la agenda del Mercosur-OMC, principalmente frente a las reaciones que se generen en el organismo cuando se consolide el proceso subregional como una unión aduanera.

\section{La economía politica doméstica}

En el campo de la economía política doméstica los temas de la politización involucran cuestiones económicas y sociales. En este caso la discusión remite a los costos y beneficios generados por los procesos asociativos en los contextos locales. En la Argentina este debate se superpone a las reacciones producidas por el amplio programa de estabilización y liberalización económica puesto en marcha a partir de principios de los años noventa. La participación en el Mercosur y en particular la asociación con Brasil son percibidas como una entre tantas dimensiones de este mismo proceso. Para los sectores más identificados con los cambios producidos por la reforma económica, la preocupación central se tornó la diferencia de ritmo y la extensión de la política de estabilización adoptada en Brasil y los riesgos de que en el contexto de una vinculación asimétrica esta asintonía pudiese afectar los resultados obtenidos por el Plan de Convertibilidad. Para algunos segmentos críticos a la política económica del gobierno, el temor principal pasó a ser que la integración subregional profundizara el proceso de desindustrialización del país (28). Del lado brasilero pudieron observarse preocupaciones semejantes, si bien en un sentido inverso. Las reacciones partían no sólo de los sectores menos competitivos frente a los productos ofrecidos por los socios del Cono Sur sino también de aquellos más sensibles a la competencia internacional. En este cuadro, la integración regional pasó a ser identificada como un primer paso para la plena apertura y desregulación de la actividad económica en Brasil.

Dos macro cuestiones emergen en este debate: una se vincula al ámbito de la producción y otra a la del trabajo. En ambas la problemática remite al papel del Estado y de su proyección institucional sobre el mercado en el contexto de un proceso de integración regional. En el primer caso se pone en cuestión la necesidad o no de compromisos extensivos de los gobiernos junto a los intereses industriales locales, la prioridad o no de que se mantengan o se creen iniciativas de protección que pudieran interferir en negociaciones interestatales ya consumadas (29). En el segundo caso sobresalen dos temas interrelacionados: el de las legislaciones laborales (incluyendo la reglamentación de profesiones) y el de las políticas migratorias. La incidencia de condicionantes políticos y económicos locales se torna aun más importante en vista del carácter crítico de la agenda social para todos los Estados miembros del Mercosur. En este sentido, si bien el 
surgimiento de la cuestión social en el proceso de integración regional se relaciona con el nivel y el tipo de asimetrías económicas entre los Estados miembros, está también determinada por realidades previas o que se desenvuelven concomitantemente. Desde el punto de vista político, la ausencia de medidas institucionales que amplien los instrumentos de regulación y protección al trabajo conjuntamente con la vigencia de políticas de flexibilización laboral, podrá profundizar la politización anti-integracionista en los medios sindicales mercosuleños.

Es necesario mencionar que la politización suscitada en el ámbito de la economía política doméstica tiene lugar en todos los países del Mercosur. Guardando la especificidad de cada dinámica local de los intereses societales y políticos, este se ha vuelto el principal campo de controversias en el Mercosur.

\section{Politica externa y seguridad internacional}

Dos problemáticas emergen en el caso de la politización generada con respecto a la política externa y de la seguridad internacional. La primera se refiere al grado de coordinación necesaria entre estas políticas y el proceso de interdependencia económica y la segunda al impacto per se de este proceso sobre las condiciones de seguridad de los Estados miembros del Mercosur (30).

Se trata, en este caso, de enfocar el modelo de vinculación entre las relaciones económico-comerciales, la política internacional y de seguridad regional y su proyección sobre las relaciones inter-estatales. Las controversias generadas involucran nuevas y viejas cuestiones de las agendas intra-regionales estimulando un embate entre visiones que privilegian políticas exteriores y de defensa de cuño autonomista y aquellas que defienden la necesidad de convergencias en un marco de seguridad cooperativa. Al mismo tiempo que las antiguas rivalidades interestatales que otrora alimentaron hipótesis de conflictos bilaterales son plenamente sepultadas, se observa un espacio para nuevas controversias sobre opciones de política internacional y de seguridad (31).

Este tipo de politización estuvo en un primer momento alimentada por interpretaciones divergentes sobre las transformaciones mundiales post-Guerra Fría al inicio de los años noventa. Una evaluación ex-post muestra entretanto que las controversias que se generaron estuvieron sobredimensionadas. En parte su exacerbación se debió al hecho de que durante la etapa de aproximación argentino-brasileña que precedió al Mercosur la coordinación de políticas externas y las posiciones convergentes en el campo de seguridad internacional tuvieron mayor relevancia que los resultados obtenidos en el campo económico-comercial. Dicho de otra forma, la interrupción de este tipo de convergencia tornó más llamativa su inexistencia en una etapa posterior. Este sobredimensionamiento 
estaba relacionado también al hecho de que el Mercosur siempre fue dirigido por las cancillerías de sus Estados miembros. Esta proximidad funcional que inevitablemente establece, una mayor vinculación entre política internacional y de integración regional en el ambito burocratico. Entretanto, la literatura sobre cooperación internacional ha destacado que intereses comunes en terrenos económicos son más fáciles de alcanzar que en áreas de política externa y de seguridad internacional (32). Para llegar a esta etapa se necesita un proceso de maduración histórica que en ningún caso se ha alcanzado hasta el presente con el Mercosur. Vale aún mencionar que el desarrollo de controversias sobre problemas externos puede precipitar crisis innecesarias y desviar la atención de los temas que realmente importan en un proceso de integración regional.

\section{El marco institucional}

Las posiciones suscitadas sobre el formato institucional del Mercosur corresponden a las interpretaciones diferenciadas sobre la mejor forma de asegurar la continuidad del proceso de integración subregional. El principal punto en cuestión se refiere a la estructura institucional más indicada para el proceso asociativo particularmente a partir de su consolidación como una Unión Aduanera. Por tratarse esencialmente de un proceso intergubernamental, este debate refleja la defensa de los intereses nacionales proyectados sobre el mismo. Se ha establecido en este caso una asociación entre el ritmo de institucionalización y el propio éxito del proceso de integración. El debate sobre el modelo institucional del Mercosur involucra tres aspectos específicos: su formato administrativo, sus recursos jurídicos y su sistema decisorio.

Se contraponen aquí dos fórmulas: el institucionalismo intergubernamental e el institucionalismo supranacional. La primera opción implicará un avance más lento y cauteloso del proceso de integración, en cuanto el segundo conduce a su aceleración. La vertiente del institucionalismo intergubernamental procura preservar a los gobiernos como actores protagónicos exclusivos, un sistema decisorio que opera por consenso alcanzada por la negociación de un mínimo denominador común y una expansión controlada de la agenda oficial del Mercosur. Un institucionalismo supranacional por su parte presupone una activa participación de grupos de interés transnacionales, la creación de una burocracia propia, la adopción progresiva de un sistema de votación calificada que valorice los intereses comunes de los Estados miembros, y la consolidación del proceso de integración a partir de una lógica expansiva (33).

En lo que concierne a la cuestión jurídica el principal debate se refiere a la eficacia del mecanismo de solución de controversias actualmente vigente en el Mercosur. Las posiciones oscilan entre aquellas que consideran excesivamente complejo el mecanismo, razón por la cual no es utilizado, y otras que defienden 
la creación de una instancia judicial más sólida siguiendo el modelo de la Corte de Luxemburgo. En este caso se podría avanzar en la creación de una legislación comunitaria ampliando considerablemente los instrumentos jurídicos del Mercosur (34).

Esta controversia está fuertemente influenciada por la estructura asimétrica del Mercosur. La adopción de una fórmula supranacional es más defendida por los Estados menores, en tanto que los socios mayores - y particularmente Brasil - han sido más favorables a mantener el modelo intergubernamental rotulada com de institucionalismo light. Esta preferencia obedece a una lógica política presente en cualquier proceso de integración regional y no ignora la necesidad de ampliar y perfeccionar la estructura administrativa del Mercosur. La tendencia verificada es que en cuanto los países pequeños puedan ser compensados con pagos laterales, los grandes ejercerán un poder de veto de facto asegurando la convergencia sobre un mínimo denominador común. En el caso del Mercosur esta dinámica ha sido comandada por Brasil y Argentina, entre los cuales el principio de reciprocidad - específica o difusa - constituye una regla implícita ( 35).

La politización generada por la cuestión institucional se desarrolla entre y dentro de los países miembros. En todos los países de la subregión los actores considerados del segundo nivel tienden a defender la creación de una estructura supranacional para el Mercosur. Esta solución es percibida como un medio para ampliar el poder de presión e influencia de los diferentes segmentos sociales y económicos afectados por el proceso de integración subregional Además de vincularse a preferencias políticas y técnicas esta controversia está fuertemente influenciada por la agenda externa del Mercosur, particularmente sus relaciones con la Unión Europea. Esta ha Estado apoyando ostensiblemente la profundización de este debate entre los socios del Mercosur dejando traslucir su preferencia por una institucionalización más sólida de este proceso. Vale recordar que las negociaciones comerciales UE-Mercosur tuvieron inicio a partir de su transformación en una Unión Aduanera.

\section{El universo ideológico}

La caracterización de las posiciones ideológicas suscitadas por el proceso de integración subregional conduce a un terreno poco explorado. Para avanzar en esta dirección una pregunta clave debe ser hecha. ¿Cuáles son las bases ideológicas de apoyo o rechazo al Mercosur?

\section{El marco conceptual}

Antes de proseguir en dirección a una respuesta conviene hacer una breve aclaración conceptual. La utilización del término ideología en este análisis se inscribe en el sentido débil del término, es decir en su definición como un sistema 
de creencias políticas, un conjunto de ideas y de valores. Sigo en este caso la definición utilizada por Bobbio, para quien la ideología en su sentido débil "designa una especie diversamente definida, de los sistemas de creencias políticas: un conjunto de ideas y de valores referidos al orden público y teniendo como función orientar los comportamientos políticos colectivos" (36).

Otro punto a ser subrayado es que tratar el universo ideológico en el cual se desenvuelve el Mercosur no significa atribuir a este proceso un significado ideológico propio. Se trata si de mostrar cual es el sistema de creencias y valores que le otorgan sustento político como también cual es su especificidad cuando son aplicadas a la integración subregional. Esta especificidad, por su parte, implica la incorporación de un componente pragmático que, al contrario de lo que sugiere Sartori, no constituye en este caso una opción contrapuesta a una acción política ideologizada (37).

Otro aspecto a ser contemplado cuando se analizan los componentes ideológicos de un proceso de integración regional es el de su relación con la tesis sobre la declinación de las ideologías. La referencia en este caso no es hecha a la versión más reciente de esta tesis, que pretende interpretar el impacto ideológico del fin de la Guerra Fría (38). Se trata si de recuperar la tesis desarrollada a mediados de los años cincuenta en el ámbito de la ciencia política, que asoció la mayor propensión al consenso político en las sociedades industriales modernas a la progresiva erosión de las ideologías tradicionales (39). Se podría establecer un paralelismo entre el contexto ideológico europeo de los años 50/60 y el que se observa durante la etapa de consolidación democrática en los países del Mercosur. De la misma forma que la desactivación de las pasiones políticas, necesaria para la formulación e implementación de políticas de bienestar en Europa generó un ambiente político favorable a la integración regional, en el Cono Sur, la menor polarización ideológica, al constituir un factor esencial de los procesos de democratización en los países de esta subregión, favoreció la construcción de una agenda de cooperación interestatal.

\section{Como encuadrar la cuestión}

Una respuesta adecuada a la pregunta lanzada al principio de esta sección presupone la vinculación entre dos problemáticas igualmente relevantes. La primera se refiere al tipo de ideologización observada en los procesos de integración regional contemporáneos. En este caso el debate generado en los últimos años en el ámbito comunitario europeo constituye una experiencia particularmente ilustrativa. La segunda problemática se refiere al marco ideológico de los procesos de consolidación democrática en los países miembros del Mercosur. En este caso se torna inevitable mencionar la economía política de estos procesos, que además de constituir el elemento de mayor relevancia para la definción del 
perfil ideológico de los respectivos gobiernos, se convirtió en el principal foco de controversia política en la subregión.

\section{El ejemplo europeo}

Desde el inicio del proceso comunitario europeo se observó una vinculación entre su impacto político y las posiciones asumidas por organizaciones partidarias de los países miembros. No obstante, fue recién cuando se reivindicó una ampliación del espacio de participación de las fuerzas políticas locales, a través de un papel más activo del Parlamento Europeo, que se estableció una diferenciación político-ideológica más nítida en torno del proyecto comunitario (40). Al mismo tiempo a medida que la CEE ganó un perfil político más autónomo, la política comunitaria dejó de ser una sumatoria de tareas técnicas con opciones políticas nacionales. La decisión de profundizar el proceso de integración europeo tornó crucial la superación de su déficit democrático creándose una dilución aún mayor entre las dimensiones políticas doméstica y regional. A partir de entonces surgió una diferenciación ideologica más nítida entre opciones de política comunitária (41).

Desde una visión simplificada, los partidos políticos que prestaron mayor apoyo al proyecto comunitario europeo fueron aquellos de perfil ideológico de centro. Los partidos de izquierda, se caracterizaron por mantener posturas antiintegracionistas, destacándose las posiciones asumidas por los partidos comunistas en Francia e Italia. Este tipo de tendencia se reprodujo en los países de incorporación posterior como España y Portugal, debiendo hacerse también mención a las banderas anticomunitarias del partido laborista de Inglaterra. Con signo ideológico opuesto pero con resultados semejantes en lo que respecta a la política comunitaria vale destacar las posiciones anti-CEE de los partidos de derecha, en especial aquellos de orientación ultranacionalista. En este caso el ejemplo paradigmático han sido las organizaciones derechistas francesas - el partido Gaullista y el Frente Nacional (42). Como contrapartida, en países como Italia, Alemania y Holanda ganaron fuerza las coaliciones inter-partidarias interesadas en fortalecer sus lazos con el proceso comunitario.

En la mayoría de los países miembros de la Ue la movilización políticopartidaria en torno de la cuestión comunitaria fue lenta. Fue difícil crear una vinculación activa y permanente entre el electorado europeo y el proceso de integración y sólo a partir del Tratado de Maastrich la distancia entre el ámbito de la política regional y la nacional comenzó a diluirse. A partir de entonces se observó una europeización de la política doméstica a través de la cual la dinámica política y económica de la UE se tornaron parte de la lógica institucional y decisoria de la actividad política europea (43).

Para completar el cuadro se debe mencionar que la principal motivación política del proceso comunitario europeo, a partir de mediados de los años 80 , 
fue la convergencia inter-gubernamental en torno de políticas económicas de orientación neoliberal. La ola de programas nacionales de desregulación económica llevó a que la Comunidad fuese percibida como un instrumento para la remoción de barreras y no como un medio de intervención económica. Como fue comentado por Hoffman y Keohane la "semejanza subjetiva" entre los principales miembros de la CEE, propiciada por este nuevo marco de coincidencias, se transformó en una condición esencial para la negociación del Acta Unica Europea (44).

\section{Consolidación democrática y neoliberalismo}

Existe una gran coincidencia en los análisis sobre los contextos políticoideológicos de los procesos de consolidación democrática en el Cono Sur. Se tornó consensual la asociación de estos procesos y el predominio de idearios neoliberales, destacándose la importancia de los actores e intereses externos para que tal asociación ocurriese.

El hecho de que la consolidación democrática en la mayoría de los países del área se haya desarrollado en un contexto de ajustes económicos estructurales generó un nuevo tipo de vinculación entre el ámbito de la política y de la economía cuya aprobación o crítica pasaron a indicar una señalización ideológica (45). La aprobación o rechazo de las premisas incluidas en el difundido Consenso de Washington pasaron a articularse a sistemas de creencias que, a pesar de que se expresaron en un mundo de post-Guerra Fría, guardan un fuerte sentido ideológico. El debate sobre la inevitabilidad de los programas de estabilización, el impacto político-institucional de las medidas de desregulación del mercado, la dinámica incremental de sus respectivos costos sociales y la difícil viabilización de propuestas alternativas se tornaron los elementos más importantes para la definición de nuevas polaridades ideológicas.

En este marco la vigencia de regímenes democráticos representativos e institucionalizados en los países de la subregión adquirió características peculiares. El contexto de una crisis generalizada de sus respectivos Estados, la sobrevivencia de determinados vicios políticos de la etapa autoritaria y el vaciamiento ideológico del sistema político-partidario generaron las condiciones para el surgimiento de lo que O’Donnell calificó de “ciudadanía de baja intensidad" (46). En este contexto el limitado liberalismo político practicado por las instituciones que sustentan estas democracias constituiría uno de los principales factores que atrofia el ejercicio de la ciudadanía.

Habiendo recorrido caminos notablemente diferentes, las democracias de la Unión Europea y del Mercosur comparten una señalización ideológica semejante. El punto de unión entre ambas experiencias son las convergencias entre las políticas de liberalización y desregulación económica. Desde el punto 
de vista ideológico estas políticas vienen siendo ejecutadas por gobiernos de centro. En el Cono Sur estos se convirtieron en la principal alternativa después que los países de la región llegaron al fondo del pozo de sus procesos de desestabilización económica, lo que contribuyó para debilitar las bases de apoyo de las fuerzas extremistas - tanto de derecha como de izquierda.

En la Europa comunitaria, el fin de la Guerra Fría tuvo un impacto importante sobre su geografía política tradicional. A partir de la declinación de la vieja díada ideológica, se reduz la polarización entre los extremos al mismo tiempo en que se amplió el espectro de centro. La mayor complejidad del universo político de las grandes sociedades democráticas amplió la posibilidad de combinaciones de intereses y posiciones, llevando a una expansión del espacio intermedio entre la derecha y la izquierda. Como observa Bobbio, en este proceso el espacio del centro se diversifica, siendo posible identificar un centro más próximo a la derecha y otro más alineado con la izquierda. Estas constituyen opciones moderadas de los extremos que coexisten con un "centro indivisible, que podría llamarse de centro-centro" (47).

\section{Ideología e integración regional}

Este rápido sobrevuelo permite indicar el universo ideológico en que tanto la Unión Europea como el Mercosur operan. Naturalmente en el primer caso se trata de un contexto político más complejo en el cual se entrecruzan múltiples opciones ideológicas que coexisten en grandes sociedades democráticas. No obstante, en los dos casos la integración regional corresponde a un proyecto apoyado y conducido por fuerzas políticas de centro; sea centro-izquierda, centro-derecha o centro-centro.

En el Cono Sur, los gobiernos de transición y consolidación democrática han sido gobiernos de centro. Sus políticas han oscilado entre opciones de centro-izquierda, centro-centro y centro-derecha. Este constituye el universo ideológico de los gobernantes y de las bases de sustentación política - las constituencies - de este proceso. Trata-se de un factor político fundamental para explicar la continuidad del proceso de asociación subregional.

Sin embargo, no se apoya al Mercosur necesariamente por las mismas razones. Existen diferenciaciones en cuanto a las posiciones mantenidas con respecto a las opciones de políticas integracionistas, sea en nivel nacional o regional. Lo que se desea destacar es que estas diferenciaciones reflejan los caminos posibles del Mercosur no contemplando su eliminación ni su suspensión. Estos son los puntos de politización explorados en la sección anterior. Posiciones antiMercosur pertenecen a segmentos ideológicos extremistas sean de derecha o de izquierda pautados por la exacerbación de ideales nacionalistas o internacionalistas. 
Los sectores más moderados que se diferencian de estos extremos, sean de derecha o de izquierda, apoyan el Mercosur y tratan de establecer críticamente puentes con la centro-derecha o con la centro-izquierda.

Este tipo de diferenciación aparece cuando son enfocadas las preferencias de los actores, se de primer o segundo nivel. Tratándose de un proyecto que coincide con valores y lealtades de segmentos distintos de las elites y de representantes sociales se puede identificar las redes generacionales que actualmente producen una ideología pro-Mercosur. Dos sistemas de creencias aparecen contrapuestos. Existe un primer sistema influenciado por antiguos ideales integracionistas reforzado por valores democráticos comunes que se tornaron preponderantes a partir del fin del autoritarismo. Se torna importante en este caso llamar la atención sobre la sensibilidad política desarrollada en los años 70/ 80 a partir de experiencias comunes de privaciones políticas. El segundo sistema es aquel estimulado por las transformaciones económico-políticas mundiales según el cual el Mercosur constituye una herramienta para el ingreso de sus países en la comunidad internacional de las democracias de mercado. De forma extremadamente simplificada se podría decir que en el primer caso se incluye la mayoría de los actores considerados de segundo escalón en tanto que en el segundo sistema están aquellos identificados en el primer escalón. También siguiendo un razonamiento lineal sería posible asociar el primer sistema de creencias con una orientación ideológica de centro-izquierda y el segundo con una orientación de centro-centro o centro-derecha. Debe notarse que ambos sistemas de creencias pueden mezclarse sin que exista a priori un esquema rígido de valores y lealtades.

Para aclarar las implicaciones de este mapeo ideológico se indican a continuación las cuestiones que pertencen a los cuatro universos temáticos de politización y que han por lo tanto suscitado controversias en el ámbito de la constituency del Mercosur. Estas cuestiones fueron agrupadas de acuerdo con el mapa político-ideológico sugerido.

Las diferentes posiciones agrupadas en este cuadro no deben entenderse como un esquema inflexible de preferencias. Por el contrario, se trata de opciones dentro de un mismo universo polİtico en que opera un consenso pro-Mercosur. En todos los casos est.n presentes opciones que tanto pueden ser defendidas por los gobiernos de los países miembros como por determinados actores que tratan de influenciar a estos mismos. En el caso de las preferencias de actores específicos se observa el surgimiento de nichos de interacción intergubernamental y/o intersocietal a partir del cual se forma gradualmente una base de intereses comunes que podrá en el futuro estimular una cultura comunitaria en la subregión. Este proceso implica la lenta construcción de una identidad colectiva y de un sentido de pertenencia que sobrepasa las fronteras nacionales (48). 
Temas de politizacion en el Mercosur

Posiciones ideológicas

\begin{tabular}{|c|c|c|}
\hline Universos temáticos & centro-derecha & centro-izquierda \\
\hline $\begin{array}{l}\text { Economia Politica } \\
\text { Internacional }\end{array}$ & $\begin{array}{l}\text { Mercosur = medio para } \\
\text { llegar al NAFTA } \\
\text { Vinculación de Chile por ALC } \\
\text { Acuerdo con NAFTA } \\
\text { antes de SAFTA }\end{array}$ & $\begin{array}{l}\text { Mercosur = } \\
\text { estrategia múltiple } \\
\text { Chile debería integrar UA } \\
\text { SAFTA debe preceder } \\
\text { al acuerdo con AFTA }\end{array}$ \\
\hline $\begin{array}{l}\text { Economía Politica } \\
\text { Doméstica }\end{array}$ & $\begin{array}{l}\text { Mercosur = estímulo de } \\
\text { política de liberalización } \\
\text { Las regiones no competitivas } \\
\text { se ajustan através de } \\
\text { mecanismos de mercado } \\
\text { Los temas sociales } \\
\text { pertenecen a la agenda } \\
\text { de cada país }\end{array}$ & $\begin{array}{l}\text { Mercosur = estímulo } \\
\text { de política industrial } \\
\text { Mercosur debe } \\
\text { comprender } \\
\text { políticas regionales } \\
\text { La agenda del Mercosur } \\
\text { debe comprender } \\
\text { una dimensión social }\end{array}$ \\
\hline $\begin{array}{l}\text { Politica exterior } \\
\text { y de seguridad } \\
\text { internacional }\end{array}$ & $\begin{array}{l}\text { Mercosur conduce } \\
\text { a la cooperación } \\
\text { política y estratégica }\end{array}$ & $\begin{array}{l}\text { Mercosur no conduce } \\
\text { a la cooperación } \\
\text { política y estratégica }\end{array}$ \\
\hline Institucionalización & $\begin{array}{l}\text { Estructura } \\
\text { exclusivamente } \\
\text { intergubernamental } \\
\text { Mecanismo } \\
\text { de solución de controversias }\end{array}$ & $\begin{array}{l}\text { Estructura combinada } \\
\text { intergubernamental } \\
\text { y supranacional } \\
\text { Tribunal de Justicia }\end{array}$ \\
\hline
\end{tabular}


Si bien es verdad que el Mercosur viene superando las expectativas económico-comerciales generadas desde la firma del Tratado de Asunción existe aún un largo camino por ser recorrido para la consolidación de una cultura política pró- integración. Por lo tanto será decisiva la identificación de una agenda política propia para el Mercosur capaz de movilizar intereses comunes de largo plazo que partan de la constatación de que los costos de no integrarse serán superiores a sus beneficios. Hoy por hoy, este tipo de percepción corresponde al universo de certezas de los segmentos que pertenecen más al primer do que al segundo nivel de actores del Mercosur.

Anexo

La actual estructura orgánica del Mercosur se compone de seis órganos. El Tratado de Asunción estableció los siguientes órganos durante el período de transición para la formación del Mercosur: El Consejo de Mercado Común, el Grupo Mercado Común, la Comisión Parlamentaria Conjunta y la Secretaría Administrativa del Mercosur. Mediante el Protocolo de Ouro Preto se crearon la Comisión de Comercio del Mercosur el Foro Consultivo Económico Social.

El Consejo del Mercado Común (CMC): es el órgano superior en la estructura decisoria y es responsable por la conducción política. Es el guardián del Tratado de Asunción, los Protocolos y acuerdos celebrados en su marco y determina las políticas fundamentales y para conformar el mercado común. Está compuesto por los ministros de relaciones exteriores y los ministros de economía de los respectivos Estados. Puede reunirse las veces que lo estime oportuno y por lo menos una vez al año lo hará con la participación de los presidentes de los Estados partes. Asimismo, quedó establecido un sistema de votación para la presidencia del CMC por órden alfabético y por un período de seis meses. Las reuniones son coordinadas por los cancilleres y pueden ser invitados otros ministros o autoridades de nivel ministerial. Las decisiones del CMC son tomadas por consenso y con la presencia de todos los Estados partes.

El Grupo Mercado Común (GMC): Es el órgano ejecutivo del Mercosur. Este órgano está integrado por 32 técnicos (ocho por país: cuatro miembros permanentes y cuatro alternos que representan a los siguientes organismos: Ministerio de Relaciones Exteriores, Ministerio de Economía o equivalentes (áreas de Industria y Comercio Exterior), Banco Central. El GMC es coordinado en cada país por su Ministerio de Relaciones Exteriores o equivalente. Es un órgano con facultad de iniciativa y las siguientes funciones: velar por el cumplimiento de las decisiones adoptadas por el Consejo, elevar propuestas al CMC etc. También 
el GMC podrá constituir los subgrupos de trabajo que sean necesarios para el cumplimiento de sus objetivos.

Los Subgrupos Técnicos de Trabajo (sGTs): Su constitución es una competencia del GMC. La mayoría fueron creados en oportunidad del Acta de Buenos Aires firmado por Argentina y Brasil en junio de 1990 y comenzaron a trabajar en la segunda mitad de dicho año. Al firmarse el Tratado de Asunción se ratifica la metodología y se integran a los SGT los representantes del Paraguay y Uruguay. Inicialmente se crearon diez SGT y luego se agregó el once. Los once subgrupos de trabajo durante el período de transición fueron: SGT 1: Asuntos Comerciales, SGT 2: Asuntos Aduaneros, sGT 3: Normas Técnicas, sGT 4: Política Fiscal Monetaria, SGT 5: Transporte Terrestre, sGT 6: Transporte Marítimo, SGT 7: Política Industrial y Tecnológica, sGT 8: Política Agrícola, sGT 9: Política Energética, SGT 10: Coordinación de Políticas Macroeconómicas, SGT 11: Relaciones Laborales.

Actualmente los grupos de trabajo son SGT 1: Comunicaciones, SGT 2: Minería, SGT 3: Reglamentos Técnicos, SGT 4: Asuntos Financieros, SGT 5: Transporte e Infraestructura, SGT 6: Medio Ambiente, SGT 7: Industria, sGT 8: Agricultura, SGT 9: Energía y SGT 10: Asuntos Laborales, Empleo y Seguridad Social.

El GMC define los alcances y objetivos de los SGTs y determina los temas tratados por cada uno de ellos. Los SGTs funcionan, acuerdan y presentan los resultados obtenidos al GMC, el cual como órgano ejecutivo resuelve y/o eleva los temas que así lo requieran para ser tratados en las reuniones del CMC del Mercosur. También se acordó que la mayor parte de las reuniones de los SGTs se realicen en la sede permanente de Montevideo.

El GMC cuenta con el apoyo de Reuniones de Ministros - p.ej. Ministros de Trabajo, de Educación, de Justicia, de Agricultura etc. - y de Reuniones Especializadas - p.ej. de Secretarios de Turismo, de Ciencia y Tecnología, de Cultura, de Medio Ambiente etc.

La Comisión de Comercio del Mercosur (CCM): mediante una propuesta argentina se creó la CCM con el fin de administrar y velar por la aplicación del Arancel Externo Común (AEC) y de los demás instrumentos de política comercial común (las prácticas desleales de comercio, las restricciones no arancelarias, el régimen de origen, la defensa de consumidor y de la competencia, las zonas francas, los regímenes automotriz, textil y azucarero etc.). La CCM está subordinada jerárquicamente al GMC y se reúne obligatoriamente al menos dos veces al mes. Tiene facultad frente a disputas comerciales y se pronuncia mediante directivas que son obligatorias para los Estados miembros. Está integrado por diez comités técnicos. 
El Foro Consultivo Económico y Social (FCES): Tiene funciones consultivas y se pronuncia mediante recomendaciones al GMC. Representa a los sectores económicos y sociales. A pesar de lo previsto en el Protocolo de Ouro Preto se constituirá a partir de 1996

La Secretaria Administrativa: tiene sede en Montevideo y sus funciones principales son:

- organizar y difundir la documentación del Mercosur;

- funcionar como centro de comunicaciones para intercambio de información y verificar el cumplimiento de plazos y compromisos asumidos en el marco de los distintos SGT;

- facilitar el contacto directo entre las autoridades del GMC;

- organizar los aspectos logísticos de las reuniones a realizarse en el marco del GMC.

La Comisión Parlamentaria Conjunta: fue establecida en el Cap VII, art. 24 del Tratado de Asunción. La Comisión se constituyó en Montevideo en diciembre de 1991. Su función es estudiar los proyectos de acuerdos específicos negociados por los Estados-partes antes de su envío a cada Poder Legislativo para su tratamiento y transmitir sus recomendaciones a los Poderes Ejecutivos. Por su parte, los negociadores de cada Estado mantendrán informados a sus respectivos Congresos sobre la evolución del Programa Mercosur.

Notas

I Ver Manuel Agosín y Diana Tussie, Globalización, Regionalización y nuevos dilemas en la política de comercio exterior para el desarrollo, El Trimestre Económico, jul./ sept. 1993.

2 Ver Kevin Featherstone, Jean Monnet and the 'democratic deficit' in the European Union, Journal of Common Market Studies, v. 32, n. 2, jun. 1994.

3 Cabe mencionar que la necesidad de cooperación interburocrática se ha traducido en un intercambio de funcionarios entre diferentes agencias gubernamentales. De este modo se observa una creciente presencia de diplomáticos en otros ministerios o secretarías vinculados a la agenda del Mercosur..

4 A partir de diversas iniciativas de un grupo de seis provincias argentinas que conforman la Comisión Regional de Comercio Exterior del Nordeste argentino (Crecena: Santa Fe, Corrientes, Entre Ríos, Chaco, Misiones y Formosa) y cuatro Estados brasileños que conforman el Consejo de Desenvolvimento do Sul (Codesul: Rio Grande do Sul, Santa Catarina, Paraná y Mato Grosso) para profundizar los vínculos entre ambas 
regiones. Este grupo reclama a los gobiernos nacionales y cancillerías de los respectivos países una mayor participación en las cuestiones de integración regional del Mercosur tales como las cuestiones fronterizas y obras de infraestructura, turismo etc. Recientemente, se estableció un Foro Permanente de Gobernadores del Crecena y Codesul como un paso más en el acercamiento entre ambas regiones fronterizas. También cabe mencionar que en Brasil se creó en la Superintendencia para el Desarrollo del Nordeste una secretaría especial para el Mercosur..

5 En los últimos tiempos se observa una creciente colaboración de círculos académicos con funcionarios de los gobiernos nacionales para debatir sobre el Mercosur, particularmente con las respectivas cancillerías nacionales. Desde 1993, mediante una iniciativa conjunta de Flacso/Argentina y Forosur se vienen desarrollando seminarios con representantes de los medios académicos, políticos y diplomáticos de los países del Cono Sur con el objetivo de promover las relaciones de cooperación e integración entre los países. A esta iniciativa se han sumado en los dos ultimos años instituciones académicas de Brasil y Chile. Ejemplos en este sentido han sido los tres seminarios: Las politicas exteriores de Argentina y de Brasil frente a un mundo en transición: diversidad, convergencia y complementariedad, en Buenos Aires, (septiembre de 1993); El Sur de las Américas en un mundo en transición: escenarios y politicas, en Buenos Aires, (septiembre de 1994); y El Sur de las Américas frente a nuevos desafíos, en Brasília, (mayo de 1995). También cabe mencionar el Grupo de Análisis sobre la Integración del Cono Sur, formado por especialistas de los paises integrantes del Mercosur. Este grupo se reune dos veces por año.

6 Para el concepto de "posicionalismo defensivo" ver Joseph Griecco, Cooperation among Nations. Europe, America and non-tariff barriers to trade, Ithaca, Cornell University Press, 1990.

7 Ver Guimarães, Eduardo; Bosco Machado, João y Pedro da Motta Veiga, Restruturação industrial em contexto de abertura e integração: um modelo para o caso brasileiro, Revista Brasileira de Comércio Exterior, n. 45, out./nov. 1995.

8 Ver Gabriel Bezchinsky y Bernardo Kosacoff, Nuevas estrategias de las empresas transnacionales en la Argentina, Revista de la Cepal, n. 52, abr. 1994.

9 De acuerdo con estimaciones recientes, de los US\$ 1.445 millones de inversión extranjera directa chilena acumulada en los noventa, el 94\% se localizó en América Latina y especialmente en Argentina que absorbió el 73\% de la inversión total y el 78\% de la radicada en América Latina. Cabe destacar que Chile ha participado activamente en varios procesos de privatización de empresas públicas argentinas, especialmente en el rubro de energía. Ver Armando di Filippo, Regionalismo abierto y empresas latinoamericanas, Pensamiento Iberoamericano, cit., p. 121-156.

10 Para un estudio más detallado de los emprendimientos llevados adelante conjuntamente por empresas argentinas y brasileñas, ver informe Argentina-Brasil: comercio, inversiones e integración física, publicado por la Embajada de Argentina en Brasil, ago. 1995. Ver también Roberto Bouzas, Integración económica e inversión extranjera: la experiencia reciente de Argentina y Brasil, Serie Documentos de Trabajo, n. 9, ISEN, Buenos Aires, sept. 1995. 
11 Un primer paso en esta dirección fue la realización de un convenio de cooperación entre entidades industriales de los 4 países (la Unión Industrial Argentina, la Confederación de Industria de Brasil, la Cámara de Industria de Uruguay y la Unión Industrial Paraguaya) se constituyó el Consejo Industrial del Mercosur.

12 En los últimos tiempos se han constituido tres agrupaciones (Grupo Brasil, Grupo Cordillera y Grupo Argentina) que nuclean a empresarios con inversiones en otros países del Mercosur para realizar lobby ante las autoridades vecinas. El primero se estableció en 1994, funcionando como un foro informal de debate e intercambio entre ejecutivos de empresas brasileñas en Argentina. Posteriormente, los empresarios chilenos que han invertido en Argentina se reunieron en una asociación denominada Cordillera que se ocupa de articular sus intereses en este mercado. En junio de 1995, un grupo de empresarios argentinos con intereses en Brasil estableció un foro denominado Grupo Argentina en São Paulo que se inspiró en el Grupo Brasil. Ver informe “Argentina-Brasil...", op. cit., p. 144; y A. di Filippo, op. cit., p. 136-137.

13 Ver H. Muñoz y F. Orrego Vicuña (comps.), La cooperación regional en América Latina: diagnóstico y proyecciones futuras, Mexico, El Colegio de México, 1987.

14 Ver Guillermo O'Donnell, The State, democratization and some conceptual problems, en W. Smith, C. Acuña y E. Gamarra (Eds.), Latin American political economy in the age of neoliberal reform, North-South Center, 1994.

15 Ver Graciela Bensusan, Entre candados y dientes. La agenda laboral del TLCAN, Perfiles Latinoamericanos, n. 4, jun. 1994, p. 109-141.

16 BID, Políticas para micro, pequeñas y medianas empresas. Proyecto e implementación de una red de integración empresarial para el sector Pymes, Programa de Apoyo Técnico para la Implementación y Puesta en Marcha del Mercosur, mayo 1994.

17 Ver Gatto y Ferraro, Cooperación empresarial en el Mercosur. Primeros elementos que surgen de un trabajo de campo en Argentina y Brasil, Proyecto Intal /Cepal sobre acuerdos empresariales en el Mercosur, Buenos Aires, mayo 1994; y F. Gatto y G. Yoguel, Las PyMEs argentinas en una etapa de transición productiva y tecnológica, en B. Kosacoff (comp.), El desafío de la competitividad, Cepal/Editorial Alianza, 1993. Ver también Virginia Moori-Koenig y Gabriel Yoguel, Competitividad de las PyMEs autopartistas en el nuevo escenario de apertura e integración subregional, Documento de Trabajo CFI-Cepal, n. 30, Cepal, Buenos Aires, sept. 1992.

18 Ver Victor Tokman y José Wurgaft, Integración económica y mercado de trabajo, São Paulo en Perspectiva, v. 9, n. 1, jan./mar 1995.

19 Ver Maria Silvia Portella de Castro, Considerações sobre o emprego nos processos de integração comercial e as propostas sindicais no contexto internacional e no âmbito do Mercosul, trabajo presentado en el Seminario Processos de Integração Regional e as Respostas da Sociedade: Argentina, Brasil, México e Venezuela, Universidade de São Paulo, Instituto de Estudos Avançados, 7 y 8 de agosto de 1995.

20 Para un análisis de las posiciones del sindicalismo uruguayo frente al Mercosur, ver Jorge Notaro, El tránsito al Mercosur y sus impactos en las relaciones de trabajo. El escenario regional y las economías pequeñas, Cuadernos del CLAEH, n. 69, jun. 1994, p. 93-107. 
21 Ver Tullo Vigevani y João Paulo Veiga, Mercosur: interesses e mobilização sindical, trabajo presentado en el Seminario Processos de Integração Regional e as Respostas da Sociedade: Argentina, Brasil, México e Venezuela, Universidade de São Paulo, Instituto de Estudos Avançados, 7 y 8 de agosto de 1995.

22 Joseph Nye, Comparing common markets: a revised neofuncionalist model, en Friedrich Kratochwil y Edward D. Mansfield (eds.) International organization reader, New York, Harper Collins, 1994, p. 288.

23 Idem, Comparing common markets: a revised neofuncionalist model, Regional integration: theory and research, Cambridge, Harvard University, 1971, p. 219-20.

24 Ver Pedro da Motta Veiga, Mercosur: a agenda de consolidação interna e os dilemas da ampliação, São Paulo en Perspectiva, v. 9, n. 1, ene./mar. 1995.

25 Para un análisis más detallado de este tema, ver Roberto Bouzas, La agenda económica del Mercosur: desafíos de política a corto y mediano plazo, $D T$ 194, Flacso/Argentina, 1995. Ver también La integración abierta. La Unión Europea y el Mercosur y el orden internacional, Informe Forum Euro-Latinoamericano, Instituto de Estudos Estratégicos e Internacionais, 1995.

26 Ver João Paulo dos Reis Velloso (coord.) Mercosul \& NAFTA. O Brasile a integraçao hemisférica, Rio de Janeiro, José Olympio, 1995.

27 Ver Gilson Schwartz,Mercosul entre SAFTA e NAFTA: uma reestruturação destrutiva ou integração pan-americana?, São Paulo en Perspectiva, op. cit. Se ha planteado también un debate sobre la conveniencia de Chile de estrechar las relaciones comerciales con el NAFTA o el Mercosur; ver, por ejemplo, Andrea Butelmann, Elements of Chilean trade strategy: the United States or Mercosur ?, Roberto Bouzas \& Jaime Ros (Eds.) Economic integration in the western hemisphere, Notre Dame, University of Notre Dame Press, 1994.

28 Ver A. López, G. Lugones y F. Porta, Comercio y competitividad en el Mercosur. Factores macroeconómicos, políticas públicas y estrategias privadas, DT 12, CENIT, jul.1993; Monica Hirst, Gabriel Bezchinsky y Fabián Castellana, A reação do empresariado argentino diante da formação do Mercosur, Texto para Discussão, n. 337, Ipea, mayo 1994.

29 Ver Cepal, La situación de la industria paraguaya frente al desafío de la integración en el Mercosur, 1992.

30 Sobre las diferencias en materia de política exterior y seguridad internacional, ver los informes Las políticas exteriores de Argentina y de Brasil frente a un mundo en transición: diversidad, convergencia y complementariedad, Funag, Brasília; El Sur de las Américas en un mundo en transición: escenarios y políticas, Buenos Aires, Flacso /Argentina, Forosur, ene. 1995; El Sur de las Américas frente a nuevos desafíos, Brasília, Funag, nov. 1995.

31 El auge de este tipo de politización se dio con el trabajo de Carlos Escudé y Andrés Fontana. Ver Carlos Escudé y Andrés Fontana, Divergencias estratégicas en el Cono Sur: las políticas de seguridad de la Argentina frente a las del Brasil y Chile, DT . n. 20, Universidad Torcuato Di Tella, jul. 1995. 
32 Ver Robert Jervis, Realism, game theory, and cooperation, World Politics, v. XL, n. 3 , abr. 1988.

33 Para un análisis sobre las diferencias entre el intitucionalismo intergubernamental y supranacional aplicados a la experiencia europea ver Andrew Moravcsik, Negotiating the single European Act, en Robert Keohane \& Stanley Hoffmann (Eds.) The new European Community. Decisionmaking and institutional change, Boulder, Westview Press, 1991. Para un analise sobre la metodologia de integracion del Mercosur ver Felix Peña, La construccion del Mercosur: un caso de metodologia de integración entre naciones soberanas nov. 1995 [mimeo].

34 Para un análisis comparativo de los mecanismos de solución de controversias del Mercosur y la Unión Europea, ver Inés Calceglia, La resolución de controversias en esquemas de integración. El caso Mercosur, Buenos Aires, La Ley, 1995; Marcelo Halperín, Los particulares y el Mercosur. El Protocolo de Brasilia para la solución de controversias, La Ley, año LVI, n. 31, 13 feb. 1992; Deisy de Freitas Lima Ventura, Os dilemas da institucionalizacão: um turning point para o Mercosul, São Paulo em Perspectiva, op. cit.

35 Para el concepto de reciprocidad difusa y específica ver Robert Keohane, Reciprocity in international relations, en R. Keohane International institutions and State power. Essays in international velations theory, Boulder, Westview Press, 1989.

36 Mario Stoppino, Ideologia, en Norberto Bobbio, et. al., Dicionário de política, Brasília, Editora Universidade de Brasília, 1986, p. 585. Ver también Karl Mannheim, Ideology and utopia, Londres, Routledge \& Kegan, 1960; J. Plammenatz, Ideology, Londres, MacMillan, 1971.

37 Según Sartori no todos los sistemas de creencias políticas son ideológicos ya que el pragmatismo también es un Estado del sistema de creencias. Ver Giovanni Sartori, Politics, ideology and belief systems, en American Political Science Review, v. LXII, n. 2, 1969.

38 Ver Francis Fukuyama, The end of history?, National Interest, Verano, 1989.

39 La tesis del fin de las ideologías de los años 50 surgió inicialmente en la ciencia social americana y coincidió con la expansión económica de la posguerra. Se suponía que en las sociedades democráticas desarrolladas las ideologías ya no eran necesarias debido a que se había logrado un consenso básico sobre las metas políticas que se materializó en el Estado de Bienestar. Sobre este debate, ver por ejemplo Daniel Bell, The end of ideology: on the exhaustion of political ideas in the 1950s, New York, Free Press, 1965; Chaim Waxman (org.) End of ideology debate, New York, Funk \& Wagnalls, 1968; Andrew Vincent, Ideologias politicas modernas, Rio de Janeiro, Zahar, 1995.

40 Hasta 1979 los miembros del Parlamento Europeo (PE) eran designados por los parlamentos nacionales, de manera que los partidos que no estaban representados en las legislaturas nacionales no podían integrarlo. Desde 1979 en que se celebraron las primeras elecciones directas del PE el número de grupos y de partidos políticos se incrementó sustancialmente. Además, junto al proceso de democratización del Parlamento se han ampliado también sus facultades y poderes como consecuencia de las enmiendas establecidas por el Acta Unica Europea (1985) y el Tratado de la Unión 
Europea (1992). Ver Neill Nugent, The government and politics of the European Union, London, MacMillan, 1994; Guy Peters, Bureaucratic politics and the institutions of the European Community, A. Sbragia (Ed.) Europolitics. institutions and policymaking in the new European Community. Washington DC, The Brookings Institution, 1992; John Pinder, European Community. The building of a union, Oxford University Press, 1991.

41 Geoffrey Pridham, European elections, political parties and trends of internalization in community affairs, Journal of Common Market Studies, v. XXIv, n. 4, jun. 1986, p.287.

42 La pérdida de la identidad nacional y la disminución del poder del Estado centralizado han sido cuestiones que ocupan un lugar central en el debate ideológico europeo. En el caso de Francia, ambas la izquierda jacobina y la derecha gaullista rechazaron el Tratado de Maastrich, por distintas razones. Ver Robert Ladrech, Europeanization of domestic politics and institutions: the case of France, en Journal of Common Markets Studies, v. 32, n. 1, mar. 1994, p. 74; Mark Franklin, Michael Marsh y Lauren McLaren Uncorking the bottle: popular opposition to European unification in the wake of Maastricht. Journal of Common Markets Studies, v. 32, n.4, dic. 1994.

43 Ver Robert Ladrech, op. cit.

$44 \mathrm{El}$ factor fundamental que hizo posible que esa semejanza subjetiva reapareciera en Europa fue el profundo cambio de la política económica de Francia a partir de 1983. Después del fracaso de la política económica regulada, con fuerte intervención del Estado y orientada a la autarquía, del período 1981-83, el gobierno de Mitterrand adoptó un programa económico de neto corte neoliberal. Ver Robert Keohane y Stanley Hoffmann, Insitutional change in Europe in the 1980s, en R. Keohane y S. Hoffmann (eds.) The new European Community. Decisionmaking and institutional change, Boulder, Westview Press, 1991.

45 Sobre este tema ver por ejemplo, José L. Fiori, Em busca do dissenso perdido. Rio de Janeiro, Insight Editorial, 1995.

46 Ver Guillermo O’Donnell, op. cit.

47 Norberto Bobbio, Derecha e izquierda, Madrid, Taurus, 1995, p. 56.

48 Según el análisis de los datos del Latinobarómetro, realizado por María Braun y Helena Rovner, la idea de la integración latinoamericana y particularmente de la integración en el Mercosur es altamente aceptada por la opinión pública de los países miembros pero aún existe simultáneamente bajo nivel de confianza en los países vecinos. Ver María Braun y Helena Rovner, Los ciudadanos frente al Mercosur. Trabajo presentado en el II Congreso Nacional de Ciencia Política, organizado por la SAAP. Mendoza, 1-5 de noviembre de 1995. 
Referências bibliográficas

ACHARD, Diego; SILVA FLORES, Manuel \& GONZALEZ, Luis Eduardo. Las élites argentinas y brasileñas frente al Mercosur. Buenos Aires, BID-INTAL, 1994.

AGOSÍN, Manuel \& TUSSIE, Diana. Globalización, regionalización y nuevos dilemas en la política de comercio exterior para el desarrollo. El Trimestre Económico, jul./ sept. 1993.

BELL, Daniel. The end of ideology: on the exhaustion of political ideas in the 1950s. New York, Free Press, 1965.

BENSUSAN, Graciela. Entre candados y dientes. La agenda laboral del TLCAn. Perfiles Latinoamericanos, n. 4, jun. 1994.

BEZCHINSKY, Gabriel \& KOSACOFF, Bernardo. Nuevas estrategias de las empresas transnacionales en la Argentina. Revista de la Cepal, n. 52, abr. 1994.

BID, Políticas para micro, pequeñas y medianas empresas. Proyecto e implementación de una red de integración empresarial para el sector Pymes. Programa de Apoyo Técnico para la Implementación y Puesta en Marcha del Mercosur, mayo 1994.

BOBBIO, Norberto. Derecha e izquierda. Madrid, Taurus, 1995.

BOLDORINI, María Cristina \& CZAR DE ZALDUENDO, Suzana. La estructura jurídico-institucional del Mercosur después del Protocolo de Ouro Preto. Boletín Informativo Techint, n. 283, jul./sept. 1995.

BOUZAS, Roberto. Integración económica e inversión extranjera: la experiencia reciente de Argentina y Brasil. Serie Documentos de Trabajo, n. 9, Buenos Aires, Isen, sept. 1995.

BRAUN, María \& ROVNER, Helena. Los ciudadanos frente al Mercosur. Trabajo presentado en el II Congreso Nacional de Ciencia Política, organizado por la Saap en Mendoza, 1-5 de noviembre de 1995.

CALCEGLIA, Inés. La resolución de controversias en esquemas de integración. El caso Mercosur. Buenos Aires, La Ley, 1995.

CEPAL. Sintesis de la Reunión sobre complementación productiva de lso paises miembros del Mercado Común del Sur. Santiago de Chile, LC/R. 1528, 18 mayo 1995.

CEPEDA, H. \& YOGUEL, G Las Pymes frente a la apertura externa y el proceso de integración subregional. DT, n. 13, Instituto para el Desarrollo Industrial, dic. 1993.

CHALOULT, Yves. O Mercosur e a Alcsa. Formação de uma área de libre comércio na América do Sul. Boletim de Integração Latino-americana, n. 15, out./dez. 1994.

DA MOTTA VEIGA, Pedro. Mercosur: a agenda da consolidaçao e os dilemas de ampliaçao", en João Paulo dos Reis Velloso (coord.), Mercosur \& Nafta. O Brasil e a integração hemisférica. Rio de Janeiro, José Olympio, 1995. 
DE LA BALZE, Felipe (comp.). Argentina y Brasil enfrentando el siglo XXI. Buenos Aires, Cari-Abra, 1995.

DE PAULA, José Alves. O Subgrupo 11 do Mercosur: balanço de suas atividades. Boletim de Integração Latino-americana, n. 15, out./dez. 1994.

DI FILIPPO, Armando. Regionalismo abierto y empresas latinoamericanas. Pensamiento Iberoamericano, n. 26, jul./dic. 1994.

FARIA, Werter. Órgãos de integração e instituções parlamentares internacionais. Brasília, Associação Brasileira de Estudos da Integração, 1994.

FRANKLIN, Mark; MARSH, Michael \& McLAREN, Lauren. Uncorking the bottle: popular opposition to European unification in the wake of Maastricht. Journal of Common Markets Studies, v. 32, n. 4, dic. 1994.

FUNCEX. Um balanço do Mercosul. Revista Brasileira de Comércio Exterior, n. 41, out./dez. 1994.

FUNDAÇÃO SEADE. Mercosul, São Paulo em Perspectiva, v. 9, n. 1, jan./mar. 1995.

GATTO \& FERRARO. Cooperación empresarial en el Mercosur. Primeros elementos que surgen de un trabajo de campo en Argentina y Brasil. Proyecto Intal/Cepal sobre acuerdos empresariales en el Mercosur, Buenos Aires, mayo 1994.

GATTO, F. \& YOGUEL, G. Las PyMEs argentinas en una etapa de transición productiva y tecnológica. En B. Kosacoff (comp.), El desafío de la competitividad. Cepal/Editorial Alianza, 1993.

GOULART, Linda; ARRUDA, Carlos Alberto y VINAGRE BRASIL, Haroldo. Empresas brasileiras. A evolução na dinâmica de internacionalização. Revista Brasileira de Comércio Exterior, n. 41, out./dez. 1994.

GRANDI, Jorge. A formação de quadros para a integração da América Latina. Revista Brasileira de Comércio Exterior, n. 39, abr./jun. 1994.

GRIECO, Joseph. Cooperation among Nations. Europe, America and non-tariff barriers to trade. Ithaca, Cornell University Press, 1990.

GUIMARÃES, Eduardo; MACHADO, João Bosco \& DA MOTTA VEIGA, Pedro. Restruturação industrial em contexto de abertura e integração: um modelo para o caso brasileiro. Revista Brasileira de Comércio Exterior, n. 45, out./dez. 1995.

HINOJOSA, Raúl; JEFFREY, Lewis \& ROBINSON, Sherman. Mercosur e Nafta: convergência e divergência na integração das Américas. En João Paulo dos Reis Velloso (coord.), Mercosur \& Nafta. O Brasil e a integração hemisférica, Rio de Janeiro, José Olympio, 1995.

HIRST, Monica, BEZCHINSKY, Gabriel y CASTELLANA, Fabián. A reação do empresariado argentino diante da formação do Mercosul. Texto para Discussão, n. 337, Ipea, maio 1994.

INFORME Argentina-Brasil: Comercio, Inversiones e Integración Física, publicado por la Embajada de Argentina en Brasil, ago. 1995. 
JERVIS, Robert. Realism, game theory, and cooperation. World Politics, v. XL, n. 3, abril de 1988 .

KEOHANE, Robert \& HOFFMANN, Stanley. Insitutional change in Europe in the 1980s. En R. Keohane y S. Hoffmann (eds.), The new European Community. decisionmaking and institutional change. Boulder, Westview Press, 1991.

LADRECH, Robert. Europeanization of domestic politics and institutions: the case of France. Journal of Common Markets Studies, v. 32, n. 1, mar. 1994.

MASSI, Fernando. Paraguay y el Mercosur: posibilidades en un mercado ampliado. Cuadernos de Discusión. Asunción, Centro de Análisis y Difusión de Economía Paraguaya, feb. 1995.

MOORI-KOENIG, Virginia \& YOGUEL, Gabriel. Competitividad de las Pymes autopartistas en el nuevo escenario de apertura e integración subregional. Documento de Trabajo CFI-Cepal, n. 30, Buenos Aires, Cepal, sept. 1992.

MORAVCSIK, Andrew. Negotiating the single European act. En R. Keohane y S. Hoffmann (eds.) The new European Community. Decisionmaking and institutional change. Boulder, Westview Press, 1991.

MUÑOZ, Heraldo \& ORREGO VICUÑA, F. (comps.). La cooperación regional en América Latina: diagnóstico y proyecciones futuras. México, El Colegio de México, 1987.

NOTARO, Jorge. El tránsito al Mercosur y sus impactos en las relaciones de trabajo. El escenario regional y las economías pequeñas. Cuadernos del Claeh, n. 69, jun. 1994.

NYE, Joseph. Comparing Common Markets: a revised neofuncionalist model. En Friedrich Kratochwil y Edward D. Mansfield (eds.) International organization reader. New York, Harper Collins, 1994.

O’DONNELL, Guillermo. The State, democratization and some conceptual problems. En W. Smith, C. Acuña y E. Gamarra (eds.), Latin American political economy in the age of neoliberal reform. North-South Center, 1994.

OMAN, Charles. Globalização/regionalização. O desafío para os países em desenvolvimento. Revista Brasileira de Comércio Exterior, n. 39, abr./jun. 1994.

PEREIRA, José Matias. A defesa da concorrência no Mercosul. Boletim de Integração Latino-americana, n. 15, out./dez. 1994.

PORTELLA DE CASTRO, Maria Siliva. Considerações sobre o emprego nos processos de integração comercial e as propostas sindicais no contexto internacional e no âmbito do Mercosul. Trabajo presentado en el Seminario Processos de Integração Regional e as Respostas da Sociedade: Argentina, Brasil, México e Venezuela. Universidade de São Paulo, Instituto de Estudos Avançados, 7 y 8 de agosto de 1995.

PRIDHAM, Geoffrey. European elections, political parties and trends of internalization in community affairs. Journal of Common Market Studies, v. XXIV, n. 4, jun. 1986. 
SARTORI, Giovanni. Politics, ideology and belief systems. American Political Science Review, v. LXIII, n. 2, 1969.

STOPPINO, Mario. Ideologia. En Norberto Bobbio, et. al. Dicionário de Política, Brasília, Editora Universidade de Brasília, 1986.

TOKMAN, Victor \& WURGAFT, Jose. Integración económica y mercado de trabajo. São Paulo en Perspectiva, v.. 9, n. 1, jan./mar. 1995.

UDAPEX. Bolivia y el orden internacional emergente. Ministerio de Relaciones Exteriores y Culto de Bolivia, 1995.

VIGEVANI, Tullo \& VEIGA, João Paulo. Mercosul: interesses e mobilização sindical. Trabajo presentado en el Seminario Processos de Integração Regional e as Respostas da Sociedade: Argentina, Brasil, México e Venezuela, Universidade de São Paulo, Instituto de Estudos Avançados, 7 y 8 de agosto de 1995.

VINCENT, Andrew. Ideologias políticas modernas. Rio de Janeiro, Zahar, 1995.

WAXMAN, Chaim (org.). End of ideology debate. New York, Funk \& Wagnalls, 1968.

Monica Hirst é professora da Faculdad Latinoamericana de Ciencias Sociales (Flacso), Argentina.

Texto apresentado no seminario Processos de Integração Regional e as Respostas da Sociedade: Argentina, Brasil, México e Venezuela, organizado pela Área de Assuntos Internacionais do Instituto de Estudos Avançados nos dias 7 e 8 de agosto de 1995.

A autora agradece a assistência de Elsa Llenderrozas e Marcos Mendiburu. 